\title{
Artificially Induced Polyploidization in Lobularia maritima (L.) Desv. and Its Effect on Morphological Traits
}

\author{
Renwei Huang1, Daofeng Liu', Min Zhao, Zhineng Li, Mingyang Li, \\ and Shunzhao Sui ${ }^{2}$ \\ Chongqing Engineering Research Center of Floriculture, Key Laboratory of \\ Horticulture Science for Southern Mountainous Regions of Ministry of \\ Education, College of Horticulture and Landscape Architecture, Southwest \\ University, Chongqing 400715, China
}

Additional index words. polyploidy, colchicine, tetraploid, chromosome, morphological characteristics

\begin{abstract}
Lobularia maritima (L.) Desv. is an important ornamental plant. We investigated an efficient method to induce tetraploid plants of $L$. maritima (L.) Desv. by treating germinating seeds and apical growing points of seedlings with a range of concentrations of colchicine for different periods of time. Examination of the ploidy level by counting chromosome numbers at metaphase confirmed that the chromosome number of diploid plants was $2 n=2 x=24$, whereas $2 n=4 x=48$ was observed in tetraploid plants. The morphological characteristics of the diploid and colchicine-induced tetraploid plants were compared. Increases in the size of leaves, flowers, and stomata were observed in the tetraploid plants compared with the diploids. However, the stomatal density and plant height of the tetraploid plants were lower than for the diploid plants. This study presents the first report of autotetraploid plants of $L$. maritima (L.) Desv., and of the successful generation of tetraploid plants with improved ornamental traits by colchicine treatment.
\end{abstract}

Polyploidy is widely acknowledged as a major mechanism of adaptation and speciation in plants (Ramsey and Schemske, 1998). Polyploidy is such a common component of plant evolution that it must be part of any general theory of the evolutionary ecology and genetics of plants. Furthermore, artificial polyploidization is an effective method for the generation of innovative germplasm resources suitable for selective breeding (Ye et al., 2010). Polyploid plants often possess superior agronomic traits over their diploid counterparts. For example, polyploids may have larger leaves and flowers, thicker stems and roots, darker green leaves, an increased width-to-length ratio of the leaves, and increased cell size; these characteristics lead to larger reproductive and vegetative organs, a more compact growth habit and a higher tolerance to environmental stress (Grouh et al., 2011). Moreover, polyploidy has been used in horticulture as a breeding tool to enhance ornamental characteristics, and to increase resistance to

Received for publication 2 Dec. 2014. Accepted for publication 17 Feb. 2015

This work was supported by the Key Programs of Science and Technology Commission of Chongqing (cstc2014yykfB80008), Chongqing City Board of Education (CY140201), the Doctoral Foundation of Southwest University (SWU114070), and the "111" Project (B12006).

${ }^{1}$ These authors contributed equally to this article.

${ }^{2}$ To whom reprint requests should be addressed; e-mail sszcq@swu.edu.cn. highly regarded as an astringent in the treatment of gonorrhoea. In the Amalfi Coast, Campania (Southern Italy), Lobularia maritima subsp. maritima is used in folk phytotherapy to treat abdominal pains, cold and coughs (Savo et al., 2011). L. maritima (L.) Desv. is also recognized as a Nihyperaccumulator plant, able to tolerate $1 \%$ $\mathrm{Ni}^{2+}$, and hence it has been developed for commercial application in detecting and removing heavy metals from contaminated soils (Yuan et al., 2010). Overall, however, only a limited amount of research has so far been undertaken on this species. Researches of L. maritima (L.) Desv. are mainly focused on cultivation and management, rapid propagation in vitro. Few researches have been conducted on the breeding of L. maritima (L.) Desv. However, Alyssum as an ornamental plant, the flowers of diploid plant are small and the leaves of diploid plant are linear-lanceolate to lanceolate. To improve ornamental characteristics, it is important to do researches on breeding of L. maritima (L.) Desv.

In this study, we aimed to develop an efficient method to induce tetraploid plants by treating germinating seeds and the apical growing points of seedlings with colchicine. In addition, the chromosomal, morphological and stomatal characteristics of the tetraploid plants were assessed.

\section{Materials and Methods}

environment stresses and diseases; and it can also cause variations in secondary metabolite content (Abdoli et al., 2013).

Amongst the many applicable methods for the induction of polyploidy, the use of chemicals to induce changes in chromosome number is well established (Sajjad et al., 2013). Colchicine is a compound that effectively arrests mitosis at the anaphase stage, and it is widely used to induce polyploidy in plants (Rego et al., 2011). The treatment of shoots, smaller axillary or subaxillary meristems, seeds or seedlings with colchicine is the approach traditionally used to produce polyploid plants. For example, tetraploidy in Mitracarpus hirtus L. was successfully induced by immersing leafless shoots in colchicine solution (Pansuksan et al., 2014) and tetraploidy of Crocosmia aurea was induced by treating seeds with colchicine (Hannweg et al., 2013).

Lobularia maritima (L.) Desv., a small white-flowered plant known as alyssum or sweet alyssum, is a diploid $(2 \mathrm{n}=24)$ herbaceous perennial belonging to the family Brassicaceae. It is native to southern Europe, northern Africa, the Azores, the Madeira Islands and the Canary Islands. The plant bears many branches and small fragrant flowers which appear from March to June on long raceme inflorescences. It is an important ornamental plant, planted primarily in pots and hanging baskets, at the front of flower borders, and in rock gardens; it is also highly effective as groundcover. In Spain, Alyssum is commonly used as a diuretic and antiscorbutic (Chopra et al., 1986). It is also
Plant materials. Seeds of L. maritima (L.) Desv. used in this study were supplied by Xinhui Horticulture Co., Ltd (http://www. xhseed.com/).

Colchicine treatment of germinating seeds. Seeds were placed on moistened filter paper in a $9 \mathrm{~cm}$-diameter petri dish for $20 \mathrm{~h}$ for germination to occur. The germinating seeds were then immersed in colchicine solution at a concentration of $0.05 \%, 0.1 \%$, or $0.2 \%(\mathrm{w} / \mathrm{v})$, with shaking at $100 \mathrm{rpm}$ for 6 , 12,24 , or $36 \mathrm{~h}$ in the dark at $24{ }^{\circ} \mathrm{C}$. A total of 30 seeds were used for each treatment. Germinating seeds without treatment were used as the control. Following colchicine treatment, the seeds were washed with sterile water. They were then planted in plastic pots Plantlets were maintained at 22 to $25^{\circ} \mathrm{C}$ under a 16-h photoperiod provided by cool white fluorescent with a light intensity of 60 $\mu \mathrm{mol} \cdot \mathrm{m}^{-2} \cdot \mathrm{s}^{-1}$. Survival rates were recorded one month after the colchicine treatment.

Colchicine treatment of seedlings. Seeds of L. maritima (L.) Desv. were sown in plastic pots filled with a peat and perlite mix (1:1). When the cotyledons of the emerged seedlings had expanded, a degreasing cotton ball was saturated with a solution of colchicine at a concentration of $0.05 \%$, $0.1 \%$, or $0.2 \%(\mathrm{w} / \mathrm{v})$ and wrapped around each seedling apical tip for $48 \mathrm{~h}$. The colchicine solution was reapplied to the cotton ball twice a day. A total of 30 seeds were used for each treatment. Seedlings without colchicine treatment were used as the control. Following filled with a peat and perlite mix $(1: 1)$ 
the colchicine treatment, the cotton balls were removed and the seedlings were washed with sterile water. The treated seedlings were maintained at 22 to $25{ }^{\circ} \mathrm{C}$ under a $16-\mathrm{h}$ photoperiod provided by cool white fluorescent with a light intensity of $60 \mu \mathrm{mol} \cdot \mathrm{m}^{-2} \cdot \mathrm{s}^{-1}$. Survival rates were recorded 1 month after the colchicine treatment.

Chromosome counting. The ploidy level was determined by chromosome counting in metaphasic cells (Rego et al., 2011). Chromosome detection was performed as described by Chen et al. (1979). Two months after colchicine treatment, stem tips of $\approx 3 \mathrm{~mm}$ in length were excised and pretreated with 8-oxychinoline for $3.5 \mathrm{~h}$ at room temperature and then fixed in Carnoy's solution for $2 \mathrm{~h}$. After treatment, the stem tips were washed with sterile water for $30 \mathrm{~min}$ and then hydrolyzed with cellulose-pectinase for $2.5 \mathrm{~h}$ at $30{ }^{\circ} \mathrm{C}$. After removing the enzyme solution, the stem tips were immersed in sterile water for $10 \mathrm{~min}$ and fixed in Carnoy's solution for $30 \mathrm{~min}$. Subsequently, slides were prepared by cellular dissociation and air-dried. The slides were stained with a solution of dibasic sodium phosphate: monobasic potassium phosphate $(2: 1)$ for $10 \mathrm{~min}$, and then washed with distilled water and airdried. Images of the chromosomes were captured with a c5060 digital camera (Olympus, Tokyo, Japan) interfaced to a CX31 microscope (Olympus). At least 30 cells with metaphase chromosomes were analyzed. The tetraploid induction rate was calculated as: Tetraploid induction rate $=$ Number of tetraploids $/$ Number of treated seedlings $\times 100 \%$.

Morphological measurements. The morphological characteristics of 14 tetraploid plants which chromosome number had confirmed, growing to 4-month-old plants under controlled growth conditions, were compared with 30 diploid plants. The widths and lengths of the leaves and the heights of the plants were measured using a ruler. The flower diameters, the widths and lengths of the petals, and the thicknesses of the leaves were each measured using a vernier caliper. The lengths and widths of stomata and stomatal densities were measured in the lower epidermis of mature leaves by the direct peeling method (Liang et al., 2009). The stomatal density was counted under a magnification of $\times 40$. Stomatal length and width were also measured under a magnification of $\times 40$, using an Olympus c5060 digital camera interfaced to a CX31 Olympus microscope. Statistical analysis was conducted using SPSS software and the significance of differences between diploids and tetraploids was analyzed by Student's $t$ test.

\section{Results}

Effects of colchicine applied during seed germination on the induction of tetraploidy. All of the colchicine treatments caused phytotoxic effects on the germinating seeds; most of the seedlings grew slowly and the roots became brown, and some gradually died. The survival rate and the tetraploid induction rate were all affected by the colchicine concentration and treatment time. The results showed that with increasing colchicine concentration and treatment time the survival rate clearly decreased (Table 1). After treatment with $0.1 \%$ colchicine for $36 \mathrm{~h}$, the survival rate was $60 \%$; however, after treatment with $0.2 \%$ colchicine for the same period, the survival rate was reduced to $40 \%$. There were significant differences in the survival rate among treatments. At this concentration $(0.2 \%)$, the tetraploid induction rate was at first increased and then decreased as the colchicine treatment period was lengthened. The results showed that the highest rate of tetraploid induction $(10 \%)$ was obtained when germinating seeds were treated with $0.2 \%$ colchicine concentration for a period of $12 \mathrm{~h}$.
Effects of colchicine applied to seedlings on the induction of tetraploidy. Seedlings treated for $48 \mathrm{~h}$ with colchicine grew more slowly initially than untreated control seedlings, and some of them gradually became yellow and died. The survival rate ranged from $50 \%$ to $73.3 \%$ and the rate decreased with increasing colchicine concentration; thus, the highest survival rate $(73.3 \%)$ was observed in seedlings treated with $0.05 \%$ colchicine. Using this treatment period $(48 \mathrm{~h})$, the tetraploid induction rate decreased gradually with increasing colchicine concentration; the highest induced tetraploid rate $(13.3 \%)$ was obtained when shoot apices were treated with $0.05 \%$ colchicine (Table 2). Compared with the colchicine treatment of germinating seeds, the colchicine treatment of the apical growing points of seedlings showed a higher survival rate and was more efficient.

Chromosome verification. The level of polyploidy was determined by chromosome counting of metaphasic cells from the stem tip. The results confirmed that cells of nontreated, diploid L. maritima (L.) Desv. contained $2 \mathrm{n}=2 \mathrm{x}=24$ chromosomes, whereas cells from plants which had been chromosome-verified as tetraploids had $2 \mathrm{n}=$ $4 \mathrm{x}=48$ (Fig. 1).

Morphological characteristics. Variations in the morphological characteristics of leaves and flowers were observed between diploid and tetraploid plants grown under the same conditions. Significant changes associated with chromosome doubling were recorded for important traits; statistical analysis indicated significant differences $(P<$ $0.001)$ between diploid and tetraploid plants with regard to morphological characteristics. Compared with the diploid plants, the height of the tetraploid plants was significantly reduced, with an average height decrease of $30.2 \%$. Both the width and the thickness of the leaves of tetraploid plants were increased,

Table 1. Effects of different concentrations of colchicine and treatment time on germinating seeds of Lobularia maritima (L.) Desv. and on tetraploid induction.

\begin{tabular}{|c|c|c|c|c|c|c|}
\hline Concn (\%) & Treatment time $(\mathrm{h})$ & No. of treated seedlings & No. of survivals & Survival rate $(\%)$ & No. of tetraploids & Tetraploid induction rate $(\%)$ \\
\hline 0 & 0 & 30 & 30 & $100 \mathrm{a}$ & 0 & $0 \mathrm{a}$ \\
\hline 0.05 & 12 & 30 & 24 & $80 \mathrm{bc}$ & 0 & $0 \mathrm{a}$ \\
\hline 0.05 & 24 & 30 & 22 & $73.3 \mathrm{~d}$ & 1 & $3.3 \mathrm{a}$ \\
\hline 0.1 & 6 & 30 & 24 & $80 \mathrm{~b}$ & 0 & $0 \mathrm{a}$ \\
\hline 0.1 & 12 & 30 & 23 & $76.7 \mathrm{bc}$ & 1 & $3.3 \mathrm{a}$ \\
\hline 0.1 & 24 & 30 & 20 & $66.7 \mathrm{~cd}$ & 1 & $3.3 \mathrm{a}$ \\
\hline 0.2 & 12 & 30 & 17 & $56.7 \mathrm{f}$ & 3 & $10 \mathrm{~b}$ \\
\hline 0.2 & 24 & 30 & 15 & $50 \mathrm{~g}$ & 0 & $0 \mathrm{a}$ \\
\hline 0.2 & 36 & 30 & 12 & $40 \mathrm{~g}$ & 0 & $0 \mathrm{a}$ \\
\hline
\end{tabular}

Values within a column followed by different letters differ significantly by Duncan's multiple range test at the 0.05 level of significance.

Table 2. Effects of different concentrations of colchicine on seedlings of Lobularia maritima (L.) Desv. and on tetraploid induction.

\begin{tabular}{lcccccc}
\hline Concn (\%) & Treatment time $(\mathrm{h})$ & No. of treated seedlings & No. of survivals & Survival rate (\%) & No. of tetraploids & Tetraploid induction rate (\%) \\
\hline 0 & 0 & 30 & 30 & $100 \mathrm{a}$ & 0 & $0 \mathrm{a}$ \\
0.05 & 48 & 30 & 22 & $73.3 \mathrm{~b}$ & 4 & $13.3 \mathrm{c}$ \\
0.1 & 48 & 30 & 20 & $66.7 \mathrm{c}$ & 2 & $6.7 \mathrm{~b}$ \\
0.2 & 48 & 30 & 15 & $50 \mathrm{~d}$ & 0 & $0 \mathrm{a}$ \\
\hline
\end{tabular}

Values within a column followed by different letters differ significantly by Duncan's multiple range test at the 0.05 level of significance. 
on average, by $79 \%$ and $105.9 \%$ (Table 3 ), respectively; however, the leaf index (leaf length/leaf width) of the tetraploid plants was reduced in comparison with the diploid plants (Table 3). The flower diameter, petal length, and petal width were all significantly larger in the induced tetraploids, compared with the diploids, with average increases of $42.2 \%$, $36.3 \%$, and $47.4 \%$, respectively (Fig. $2 \mathrm{~A}$ and $\mathrm{B}$; Table 3). To investigate further the characteristics of the tetraploid plants, we examined the lower epidermises of mature leaves from tetraploid and diploid plants (Fig. 3; Table 3). There were significant differences with regard to stoma size and density. The stomata length in tetraploids was about $101.6 \%$ larger than in diploids, whereas the stomata width in tetraploids was about $70.9 \%$ more than diploids (Table 3). However, there was a significant reduction in stomatal density in the tetraploid plants, as compared with the diploid plants (Table 3 ).

\section{Discussion}

Polyploidy is an attractive and challenging field of plant biology that has played an important role in plant breeding as a valuable method for inducing important morphological and physiological changes in plants (Dhooghe et al., 2011). Colchicine acts as an antimitotic agent and, as such, has been widely used to induce polyploidy in plant breeding (Grouh et al., 2011). In inducing polyploidy, the combination of colchicine concentration and treatment duration is critical. Typically, high concentrations of colchicine coupled with short durations of treatment or, conversely, low concentrations of colchicine coupled with long durations of treatment, are preferred (Ye et al., 2010). Ovaries, seeds, shoots, and axillary or subaxillary meristems have usually been used as subjects for polyploidy mutagenesis. With the sprouting seeds, in the case of Caragana intermedia, the highest tetraploid induction rate $(23.3 \%)$ was obtained following treatment with a $0.15 \%$ solution of colchicine for $36 \mathrm{~h}$ (Shen et al., 2011). In this study, germinating seeds of L. maritima (L.) Desv. were treated with colchicine solution. And the highest tetraploid induction rate $(10 \%)$ was obtained when seeds were treated with $0.2 \%$ colchicine for $12 \mathrm{~h}$.

One of the most effective methods to obtain polyploidy mutants is by colchicine treatment of seedlings with small, actively growing meristems. In Humulus lupulus L., the highest tetraploid induction rate $(25 \%)$ was obtained when apical buds were treated with $0.05 \%$ colchicine for $48 \mathrm{~h}$ (TrojakGoluch and Skomra, 2013). Similarly, in Zantedechia elliottiana, the highest tetraploid induction rate $(13.3 \%)$ was obtained when small buds generated from callus were soaked in $0.5 \mathrm{~g} \cdot \mathrm{L}^{-1}$ of colchicine for $48 \mathrm{~h}$ (Shao and Liang, 2008). Therefore, in this study, we chose to treat apical growing tips with colchicine for $48 \mathrm{~h}$, and found that the highest induced tetraploid rate $(13.3 \%)$ was obtained using a concentration of $0.05 \%$.
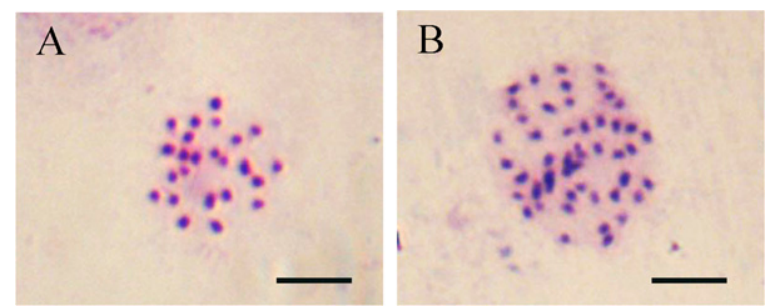

Fig. 1. Chromosome numbers of L. maritima (L.) Desv. (A) Chromosome number of diploid control plant $(2 n=2 x=24)$. (B) Chromosome number of tetraploid plant $(2 n=4 x=48)$. Bars denote $5 \mu \mathrm{m}$.

Table 3. Morphological characteristics (mean $\pm \mathrm{SE}$ ) of diploid (2x) and tetraploid $(4 \mathrm{x})$ Lobularia maritima (L.) Desv. plants.

\begin{tabular}{|c|c|c|c|}
\hline Morphological characteristic & Tetraploid & Diploid & Significance level \\
\hline Plant height $(\mathrm{cm})$ & $18.53 \pm 1.22$ & $26.56 \pm 2.46$ & $* *$ \\
\hline Leaf length $(\mathrm{cm})$ & $6.01 \pm 0.94$ & $5.73 \pm 0.60$ & NS \\
\hline Leaf width $(\mathrm{cm})$ & $1.79 \pm 0.28$ & $1.0 \pm 0.10$ & $* *$ \\
\hline Leaf thickness (mm) & $0.35 \pm 0.03$ & $0.17 \pm 0.03$ & $* *$ \\
\hline Leaf index & $3.43 \pm 0.69$ & $5.67 \pm 0.86$ & $* *$ \\
\hline Flower diameter $(\mathrm{cm})$ & $0.64 \pm 0.07$ & $0.45 \pm 0.05$ & $* *$ \\
\hline Length of petal $(\mathrm{cm})$ & $0.30 \pm 0.02$ & $0.22 \pm 0.01$ & $* *$ \\
\hline Width of petal $(\mathrm{cm})$ & $0.28 \pm 0.02$ & $0.19 \pm 0.01$ & $* *$ \\
\hline Stomatal length $(\mu \mathrm{m})$ & $31.75 \pm 1.68$ & $15.75 \pm 1.20$ & $* *$ \\
\hline Stomatal width $(\mu \mathrm{m})$ & $13.25 \pm 1.20$ & $7.75 \pm 0.79$ & $* *$ \\
\hline Stomata density $\left(\mathrm{mm}^{2}\right)$ & $32.9 \pm 8.59$ & $101.2 \pm 9.13$ & $* *$ \\
\hline
\end{tabular}

The data (mean $\pm \mathrm{SE}$ ) were obtained from 30 diploid and 14 tetraploid plants that have been grown to 4-mo. old. Statistical analysis of significant difference among diploid and tetraploid was by two-sample Student's $t$ test.

**Represents a significant difference at the $P<0.001$, and NS represents a nonsignificant difference.
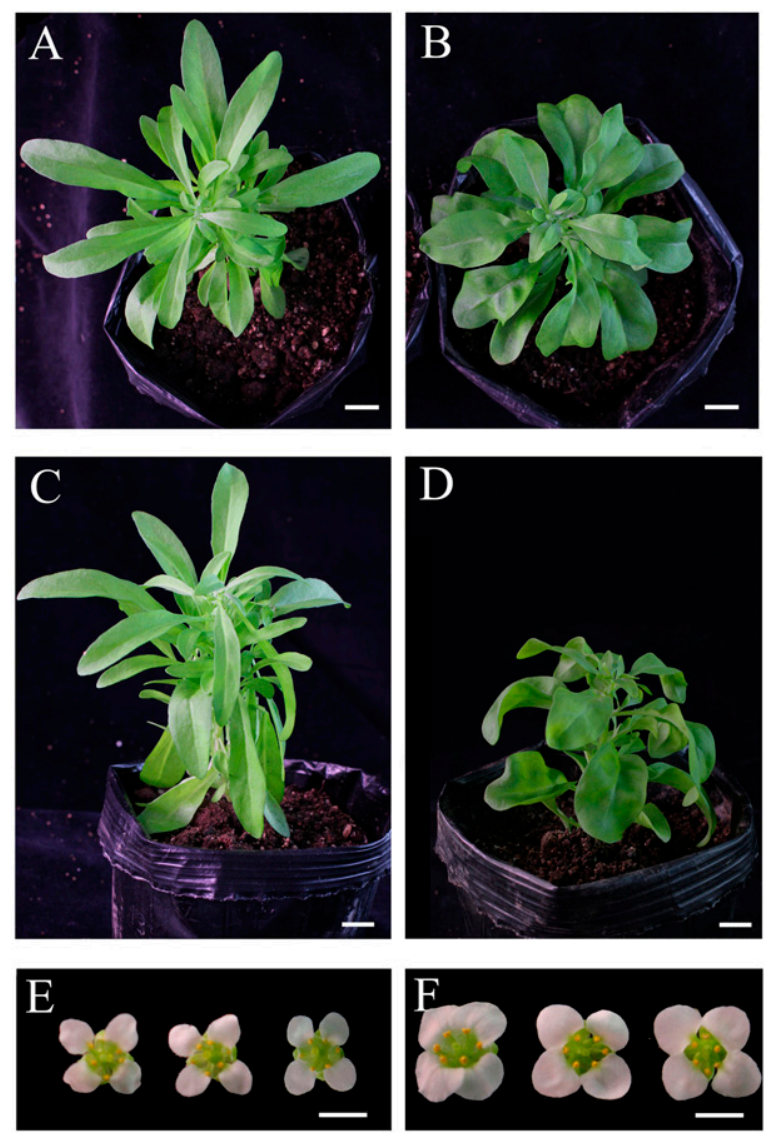

Fig. 2. Morphological characters of L. maritima (L.) Desv. (A and C) Plant morphology of diploid control plant. (B and D) Plant morphology of tetraploid plant. Bars denote $1 \mathrm{~cm}$. (E) Flowers of diploid control plant. (F) Flowers of tetraploid plant. Bars denote $3 \mathrm{~mm}$. 


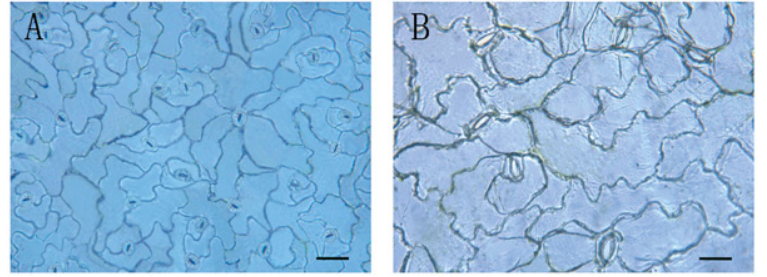

Fig. 3. Stomata of lower epidermis of L. maritima (L.) Desv. (A) Stomata of diploid concrol plant. (B) Stomata of tetraploid plant. Bars denote $30 \mu \mathrm{m}$.

There are various approaches for the identification of polyploidy in plants (Ye et al., 2010). Chromosome counting is the most direct method for the analysis of ploidy (Tang et al., 2010). In this study, chromosome detection was performed as described by Chen et al. (1979), and 14 autotetraploid plants were successfully confirmed by this method. Moreover, the results of chromosome identification showed that tetraploid plants were successfully obtained by colchicine treatment in both germinating seeds and seedlings. Comparison of the two treatment methods showed that the tetraploid induction rate for colchicine-treated apical growing tips was higher than that for colchicine-treated germinating seeds (Tables 1 and 2). This result is consistent with reports on colchicine treatment in Portulaca grandiflora Hook (Wang et al., 2010).

In many plant species, there is a correlation between ploidy level and morphological and physiological characteristics. Increases in leaf dimensions, stomata size, flower diameter, and petal length and width have been reported in tetraploid plants, such as those of $C$. aurea (Hannweg et al., 2013) and $P$. acinosa Roxb. (Yang et al., 2013a). In the present study, considerable morphological differences were observed between the diploid and the induced tetraploid plants (Figs. 2 and 3; Table 3). The significantly increased leaf size, flower diameter and stomatal dimensions seen in induced L. maritima (L.) Desv. tetraploid plants have also been observed in other plants, such as Lilium pumilum DC. (Yang et al., 2013b) and Mitracarpus hirtus L. (Pansuksan et al., 2014). These results showed that morphological and physiological characteristics can be effectively used to identify putative tetraploid of L. maritima (L.) Desv.

In conclusion, this study presents the first report of autotetraploid plants of L. maritima (L.) Desv. obtained by colchicine treatment of germinating seeds and apical growing tips of seedlings. Effective induction and the highest tetraploid mutation rate (13.3\%) were obtained when apical growing points of seedlings were treated with $0.05 \%$ colchicine for $48 \mathrm{~h}$. This study demonstrates a novel and successful application of polyploidy, with the objective of improving the ornamental value of L. maritima (L.) Desv., in particular by increasing the size of the leaves and flowers, which are important characteristics for an ornamental plant. Moreover, both the property of nickel hyperaccumulation and the secondary metabolite profile in the tetraploid plants of L. maritima (L.) Desv. should be investigated further.

\section{Literature Cited}

Abdoli, M., A. Moieni, and H.N. Badi. 2013. Morphological, physiological, cytological and phytochemical studies in diploid and colchicine-induced tetraploid plants of Echinacea purpurea (L.). Acta Physiol. Plant. 35:2075-2083.

Chen, R.Y., W.Q. Song, and X.L. Li. 1979. A new method for preparing mitotic chromosomes from plant. Acta Bot. Sin. 21(3):297-298.

Chopra, R.N., S.L. Nayar, and I.C. Chopra. 1986 Glossary of Indian medicinal plants. Council Scientific Industrial Research. p. 330. New Delhi.

Dhooghe, E., K. Van Laere, T. Eeckhaut, L. Leus, and J. Van Huylenbroeck. 2011. Mitotic chromosome doubling of plant tissues in vitro. Plant Cell Tiss Org. 104:359-373.

Grouh, M.S.H., H. Meftahizade, N. Lotfi, V. Rahimi, and B. Baniasadi. 2011. Doubling the chromosome number of Salvia hains using colchicine: Evaluation of morphological traits of recovered plants. J. Med. Plant. Res. 5 (19):4892-4898.

Hannweg, K., A. Sippel, and I. Bertling. 2013. A simple and effective method for the micropropagation and in vitro induction of polyploidy and the effect on floral characteristics of the South African iris, Crocosmia aurea. S. Afr. J. Bot. 88:367-372.
Liang, W., X.H. Yang, J.Y. Chen, and Z.Q. Zhou. 2009. A comparison of several specimen preparation methods for light microscopic observation of mulberry leaf epidermis. Sci. Seric. 35 (1):116-120.

Pansuksan, K., R. Sangthong, I. Nakamura, M. Mii, and K. Supaibulwatana. 2014. Tetraploid induction of Mitracarpus hirtus L. by colchicine and its characterization including antibacterial activity. Plant Cell Tiss Org. 117:381-391.

Ramsey, J. and D.W. Schemske. 1998. Pathways, mechanisms, and rates of polyploidy formation in flowering plants. Annu. Rev. Ecol. Syst. 29:467-501.

Rego, M.M., E.R. Rego, C.H. Bruckner, F.L. Finger, and W.C. Otoni. 2011. In vitro induction of autotetraploids from diploid yellow passion fruit mediated by colchicine and oryzalin. Plant Cell Tiss Org. 107:451-459.

Sajjad, Y., M.J. Jaskani, A. Mehmood, I. Ahmad, and H. Abbas. 2013. Effect of colchicine on in vitro polyploidy induction in African marigold (Tagetes erecta). Pak. J. Bot. 45(3):1255-1258.

Savo, V., C. Giulia, G.P. Maria, and R. David. 2011. Folk phytotherapy of the Amalfi coast (Campania, Southern Italy). J. Ethnopharmacol 135(2):376-392.

Shao, G.Y. and G.L. Liang. 2008. Polyploidy induction in Zantedeschia elliottiana. J. Zhejiang For. Coll. 25(5):630-634.

Shen, H.X., G.L. Liang, S.Y. Han, and L.W. Qi. 2011. Studies on polyploid induction of Caragana intermedia by colchicine. Acta Hortic. Sin. 38(8):1595-1600.

Tang, Z.Q., D.L. Chen, Z.J. Song, Y.C. He, and D.T. Cai. 2010. In vitro induction and identification of tetraploid plants of Paulownia tomentosa. Plant Cell Tiss Org. 102:213-220.

Trojak-Goluch, A. and U. Skomra. 2013. Artificially induced polyploidization in Humulus lupulus $\mathrm{L}$. and its effect on morphological and chemical traits. Breed. Sci. 63:393-399.

Wang, Z., D.M. Chen, C.Y. Li, R.X. Liu, M.Y. Tang, and H.R. Hu. 2010. Primary studies and identification of polyploid induction in Portulaca grandiflora Hook. Guangdong Agr. Sci. 8:74-77.

Yang, D.Y., L.Z. Zhang, J. Liu, and D.W. Sunday. 2013a. Study on induction of Phytolacca acinosa Roxb. polyploids with colchicine. J. Agr. Biotech. 2(4):23-25.

Yang, Y.J., B.B. Ge, Q. Wei, J.P. Gao, and B. Hong. 2013b. Colchicines-induced polyploid plants and identification in Lilium pumilum DC. J. China Agr. Univ. 18(1):128-133.

Ye, Y.M., J. Tong, X.P. Shi, W. Yuan, and G.R. Li 2010. Morphological and cytological studies of diploid and colchicine-induced tetraploid lines of crape myrtle (Lagerstroemia indica L.). Sci. Hort. 124:95-101.

Yuan, X.Y., X.Y. Zhang, J. Ma, and X.F. Hou. 2010. Tissue culture in vitro and Establishment of Regeneration System of Lobularia maritima. Northern Hort. 8:145-146. 